\title{
THE SHAPING A NEW UNDERSTANDING OF THE IMPACT OF HORIZON EUROPE: THE ROLES OF THE EUROPEAN COMMISSION AND MEMBER STATES
}

\author{
MATTHIAS WEBER, KATJA LAMPRECHT AND PETER BIEGELBAUER
}

DOI: 10.22163/fteval.2019.347

\section{ABSTRACT}

$\mathrm{T}$ This paper aims at tracing the process and the arguments that have led to the proposal of the $9^{\text {th }}$ European framework programme for research and innovation 'Horizon Europe'. We are particularly interested in the role and influence of member states, especially in their interplay with the European Commission, on the actual shape of the FP9 proposal, next to important contributions to this stillongoing debate, such as the interim evaluation of $\mathrm{H} 2020$, and various expert groups. The paper focuses on two of the novel elements of Horizon Europe, namely the concept of 'missions' as approach to help enhance the societal impact of 'Horizon Europe', and the proposal to establish a European Innovation Council.

\section{INTRODUCTION}

Since the establishment of the European framework programmes for research and innovation (FPs) in the mid-1980s, they have been characterised by regular change in terms of underlying narratives and intervention instruments used (Biegelbauer and Weber 2018). Decisionmaking about a framework programme follows a formalised co-decision procedure involving European Commission, European Parliament and European Council (Pollak and Slominski 2006). However, the process leading to the formulation of the proposal for a framework programme is less clearly structured. It may benefit from political leadership, such as in the case of the current Horizon 2020 programme, which draws a lot of inspiration from the Lund declaration of the Swedish European Summit. ${ }^{1}$ It also usually involves several elements of formal and informal consultations with Member States, stakeholders and experts. Overall, however, it is largely developed internally by the European Commission services.
As formulated by one of the high-level expert groups looking into this issue, there is a great deal of strategic intelligence available to feed into the development of the framework programme, but the actual sensemaking involved in the preparation of the specific proposal is opaque (EFFLA 2012). ${ }^{2}$

Given the importance of the FPs for Ryl in Europe, both in financial and in symbolic terms, the governance question of how the FPs are actually "shaped" and by whom is of major importance for the legitimacy of the entire endeavour. This leads to the main research question of this paper: How has the process of preparing the initial proposal of a framework programme worked in the case of Horizon Europe?

Inspired by work on this matter, but also through involvement in the most recent process of this kind, we argue that the influence of external stakeholders, including the Member States, on the shaping of the framework programme proposal is rather limited, and that the internal processes, dynamics and conflicts within the European Commission are the key levers of change. As a consequence, if the ambition is to strengthen the legitimacy of the framework programme, providing more transparency to the internal processes and opening it up already in the preparatory phase would be more important than yet another external consultation or call for ideas.

In order to illustrate our argument, we will look at the two main changes that are most likely going to be introduced in the new Horizon Europe programme: missions and the European Innovation Council. In what remains, we will reconstruct the process of how these two new elements came into being. An emphasis is put on the role played by Member States in influencing the emergence and specification of these new concepts. The final section will draw some conclusions based on these tentative findings. 


\section{CONCEPTUAL AND} METHODOLOGICAL FRAMEWORK

In conceptual terms, the paper draws on a network perspective on governance, and how the internal governance networks within the European Commission interact with external stakeholders and networks in the course of the shaping of the framework programme (Torfing and Sørensen 2014). These interactions exhibit features of advocacy and interest representation. Member States are part of this game and use formal as well as informal channels to bring in their views on the future shape of the framework programme (Pernicka et al 2002). However, the actors are not driven by interests alone and the whole process features also elements of policy learning (Biegelbauer 2013) in the sense of learning from past experience with previous framework programs. These interactions are all taking place in a context of discourses that shape the policy field, and which rest on policy frames and narratives produced since the early days of the European unification process (Biegelbauer and Weber 2018). In the past such frames have recurrently stressed arguments of Europe being a "laggard in S\&T" or the so-called "European Paradox". 3

We therefore focus in the analysis of our two cases (missions and European Innovation Council) on the following aspects: next to tracing their patterns of emergence, we look into the underlying rationales and narratives, and also at the role of internal and external networks for shaping them. This is complemented by a final assessment of the two cases.

In methodological terms, this paper draws on a combination of document analysis, participation in some of the preparatory processes leading to the formulation of the Horizon Europe proposal, and a series of interviews with individuals involved in that process. The insights from the interviews are still preliminary, because the interview programme has not been finished yet. Moreover, as the preparation of Horizon Europe is still an ongoing process, the analysis presented in this paper must be regarded as preliminary, too, since relevant documents are published almost every month.

\section{THE PATTERNS OF EMERGENCE OF FP9}

As foundation for the deeper analysis of the two examples of missions and EIC, it is instructive to briefly reconstruct the main phases of the shaping of Horizon Europe as a whole. Horizon 2020 started off with high ambitions regarding the role and contribution of European research and innovation funding to addressing the societal challenges that are at the core of the third pillar of Horizon 2020. However, it became soon clear that the envisaged impacts on societal challenges could at best arise in the long term and that the linkages between specific R\&l projects and higher-order policy goals like addressing societal challenges were at best vague (see e.g. European Council 2015), also because governance practices did not really change compared to previous framework programmes. In addition, the overall research and innovation performance of Europe did not meet the ambitions initially formulated by the Innovation Union flagship initiative, as shown by corresponding output indicators. A growing pressure on EU (R\&I) policy to demonstrate its value added to Member States and citizens raised the need to formulate convincing narratives in order to justify a rising, or at least stable, budgetary provision during the negotiation phase of the upcoming multi-annual financial framework (MFF). These observations may serve as backdrop for the four main phases of preparing the new framework programme.

\section{PHASE 1: EARLY THOUGHTS ABOUT A NEW FRAME- WORK PROGRAMME}

First ideas about what a new framework programme should look like were launched already in the course of 2015/16 at the level of the research commissioner's cabinet. The RISE high-level expert group identified important issues to be considered for future R\&l policy, such as i) difficulties of Europe in retaining fast-growing firms (partly due to a shortage of second-phase venture capital, partly as a result of an incomplete single market) (Soete et al. 2015), ii) the need for a more transformative and at the same time more open Ryl policy (Andree et al. 2015), iii) the "double deficit" as compared to the US in terms of lagging behind not only in innovation, but also in key areas of science (Sachwald 2015), and iv) the growing divide between Member States in terms of innovation performance (Tsipouri 2017). At national level, first initiatives were taken as well to think ahead in terms of what the next framework programme should be about (e.g. the Austrian FP9 Think Tank). The "Lund revisited" conference (European Council 2015) and the Madelin Report further fueled the early debates about "Europe's mission to innovate" (Madelin and Ringrose 2016).

\section{PHASE 2: LEARNING FROM THE PAST, AND IDENTIFY- ING CHALLENGES FOR THE FUTURE}

The culmination point of this second phase must be seen in the publication of the Lamy Report in mid-2017 (Lamy et al. 2017). Based on the interim-evaluation of Horizon 2020, the modelling of possible impacts of European research, and the foresight project BOHEMIA, the Lamy Report brought together eleven guiding principles for the next framework programme, among which also the introduction of a mission-oriented approach and support to the idea of a European Innovation Council were mentioned.

\section{PHASE 3: ELABORATING KEY ELEMENTS}

Subsequent debates led to a further refinement of the ideas on the new framework programme, in particular to the missions and the European Innovation Council. Various EC expert groups, in particular RISE (Research, Innovation and Science Policy Experts High Level Group), ESIR (Expert Group on the Economic and Societal Impact of Research 
and Innovation) and the High-Level Group of Innovators, were involved in this process. ${ }^{4}$ A policy paper by Mariana Mazzucato (Mazzucato 2018) and support studies on past experiences with missions (JIIP 2018) and future candidate themes for missions (Weber et al. 2018b) also fed into the debates.

\section{PHASE 4: FEEDBACK AND REFINEMENT}

In the second half of 2018, Member States, European Parliament and stakeholders gave feedback and made suggestions for changes to the Commission proposal. An enhanced pilot of EIC is now foreseen to be launched in 2019, in order to pave the way for the new Horizon Europe concept of the EIC. However, there are still many open questions regarding the effectiveness and governance of the EIC, as well as regarding the enhanced role of the EC as financing agent. The identification, selection and governance of missions in between the different pillars and (within pillar) clusters of Horizon Europe are still unclear, in spite of launching an extensive EC-internal preparatory process during summer 2018. The process of refinement is likely to continue even after the legal decision on Horizon Europe will have been taken.

\section{THE SHAPING OF “MISSIONS”}

\section{PATTERNS OF EMERGENCE}

The notion of missions was not used explicitly by the Commission in the debate about the next framework programme until the publication of the Lamy Report in 2017. However, already before similar ideas had been raised, which were inspired by the gap between the high ambitions of the societal challenges pillar in Horizon 2020 and the largely supply- and S\&T centric approach used to implement it (European Council 2015). Drawing on earlier work on demand-side innovation policy in the European Commission (e.g. in the Aho Report), Andree et al (2015), in a report of the RISE group advising the research commissioner, called for a demandcentric mission-oriented approach in future R\&l policy in order to move beyond the technology-centric approach of Horizon 2020: "While the move towards a challenge-driven approach in Horizon 2020 has been a good step forward, addressing now broader societal challenges, to have a real impact, such a programme would have to be truly "mission-oriented", fitting in as an integral part of larger policy objectives. To achieve this, RqI will have to be linked closer to the other EU policies, defining concrete missions in the realm of a broader EU energy policy, transport policy, environment policy, etc. In other words, what is lacking is coordination and synergies between supply and demand of R\&I." (p. 5).

The term 'mission' was explicitly used for the first time in a Commission report by Robert Madelin and David Ringrose (Madelin and Ringrose 2016), which was entitled "Opportunity now: Europe's mission to innovate". Here the notion of "mission" was used in a comprehensive sense, in order to promote a positive commitment to innovation in order "to make society attentive to its future and resilient in face of crisis" (p. 49).

After this first phase, the idea that a mission-oriented approach should be adopted in the EU framework programmes, however, was dis- cussed in several circles, as reflected, for instance, in the first theses paper of the Austrian FP9 Think Tank (FP9 Think Tank 2016), which argues that "contributing to the grand societal challenges of our times and bringing science closer to the people should be main objectives of FPI. With respect to the societal challenges element of the programme, a redesign is required to give full justice to the specificities of new mission-oriented programmes." (p. 6). Other national papers outlining first ideas about the future framework programme, came up with similar suggestions.

In the follow-up to the Lamy report, policy papers by different expert groups (RISE 2018a; ESIR 2017) further contributed to the elaboration of a mission-oriented approach in FP9. With the Mazzucato paper (Mazzucato 2018), published in early 2018, the political legitimacy of missions was further consolidated. This was necessary because missions reassign a stronger role to the state in matters not only of research, but also of innovation and diffusion. The subsequent consultation on the missionoriented approach lent a lot of support to the concept, but also raised quite some skepticism as to the governance capabilities and capacities of the European Commission to deliver on the high promises raised. This skepticism was underpinned by experiences from past mission-oriented initiatives, showing that missions require a highly developed governance and management system with strong leadership to succeed: Also a range of other critical success factors has to be taken into account, in particular when addressing 'transformative' and 'systemic' rather than just technological challenges (JIIP 2018). Moreover, the approach presented by Mazzucato (and largely adopted by the EC) seems to draw strongly on the rather technocratic experiences with "old" missions, which may well be suitable for technology-centric missions, but is less adapted to "new" missions geared towards societal challenges, which are more complex and wicked in nature.

Since the presentation of the Horizon Europe proposal, which was rather vague about the topics and the implementation modalities for missions, first steps have been made to develop a governance framework for missions. The debates about the identification and selection of priority themes for future missions to be addressed in Horizon Europe give evidence of the difficulties faced by the European Commission in bringing the missions concept to the ground, and which are reflected in a recent memorandum by the ESIR expert group (ESIR 2018). The challenges and uncertainties associated with the governance of missions in Horizon Europe are likely to be the reasons why for now only a comparative modest share of $10-15 \%$ of the budget are foreseen to be implemented under the umbrella of missions.

\section{RATIONALE: TURNING A VISION INTO PRACTICE}

Although the strengthening of an orientation of European Ryl towards societal challenges received a lot of support when Horizon 2020 was launched, it soon turned out that the gap between highly abstract challenges and the reality of specific projects was very wide. Even if explicit reference was made in project proposals to the relevance of the envisaged work for addressing societal challenges, the challenges often served only as umbrella to which lip service had to be paid. Neither was it possible to seriously assess or evaluate impacts of specific projects on 
the ability to address societal challenges, due to attribution problems resulting from the many other intervening factors and the long time horizon. What was missing was often an intermediate layer that would allow targeting ambitious but achievable goals with the help of a bundle or cluster of projects. Moreover, research and innovation activities at best promise an impact potential, but whether an actual impact will be achieved depends on demand-side conditions determining the uptake and diffusion of new solutions.

Overall, the mode of implementing Horizon 2020 did not change significantly as compared to earlier framework programmes. Guiding ideas or visions were translated in a systematic process of strategic programming and work programme development into individual topics to which consortia could apply, but limited room was given to non-conventional ideas.

In this light, missions represent an opportunity to introduce an intermediary level of orientation and guidance, in between the highly abstract societal challenges and the reality of specific projects, which should help overcome the fragmentation into a myriad of individual projects. Functionally, they describe a credible claim to make the change happen that is needed on the pathway towards successfully addressing societal challenges. A very important promise tied to this claim was the promise of impact. A clear goal, a clear timeline and a clear plan of how to bundle complementary projects into a package should contribute to achieving impact beyond the level of individual projects.

This technocratic vision of enhanced planning and implementation of research and innovation activities was meant to help overcome growing skepticism about the ability to achieve the ambitious goals tied to societal challenges under Horizon 2020. Such a convincing narrative was important to ensure support to an increase of the research budget within the multi-annual financial framework of the EU.

However, the appealing idea of missions also opened up Pandora's box. If taken seriously, a mission-oriented approach, in particular when applied to systemic and wicked challenges (e.g. circular economy, sustainable mobility, climate change) opens up many interfaces. These are primarily with policy areas and policy levels that would need to revisit the demand-side instruments and framework conditions key for the uptake of novel solutions: no uptake, no impact. This issue of who ultimately "owns" the missions has not yet been resolved. Seen from an impact perspective, sectoral policies "own" the issues to be addressed (e.g. secure and sustainable energy supply, sustainable mobility) and should therefore lead the definition of missions, but by restricting them to R\&l missions the lead could be claimed to stay within R\&l policy.

\section{EXTERNAL NETWORKS: SUPPORT FOR AN AMBITIOUS AND VAGUE GOVERNANCE APPROACH}

The simple narrative behind missions was well received by the majority of external stakeholders. Several Member States had already before adopted similar ideas in their national policies, and adapted them to their specific conditions. The Challenge-Driven Innovation programme in Sweden may serve as an example. And most recently, the German government presented 12 missions as part of its revised High-Tech Strategy 2025 (BMBF 2018).

This is also reflected in the generally rather positive reactions to the mission-oriented approach as reflected in national position papers to the Horizon Europe proposal. The main points of criticism refer to the gover- nance of the missions, and in particular to the question of respective influence of Member States and Commission on the definition, selection and subsequent implementation of missions, whereas other critical issues such as the coordination and alignment of R\&l policy with sectoral policies received less attention.

Some other stakeholders, in particular in industry, remain more reserved about the mission-oriented approach. Not only do they fear the complexity of implementation, but also declining support to traditional key enabling technologies. Others, such as many RTOs, perceive missions as an opportunity to bring their inter-disciplinary competencies and their ability to manage large-scale projects involving different stakeholders to bear in the implementation of missions.

\section{INTERNAL NETWORKS: TRICKLING DOWN OF A POLITICAL IDEA}

Internally to the European Commission, the mission-oriented approach gained support through a range of mechanisms. First of all, the societal challenges were largely supported as overarching frame, and further strengthened by the launch of the UN Sustainable Development Goals. As regards implementation, two different perspectives can be distinguished. On the one hand, the 'traditionalist stance' was in favour of the well-established approach to implementing framework programmes through thematic work programmes. On the other hand, the 'modernist stance' sought a revision of the implementation approach in order to truly deliver on the ambitions formulated with the societal challenges.

A second important concern was the autonomy of DG RTD in defining its policy agenda. The past years saw a transformation of DG RTD from a programme-implementing into a policy DG with a strong political agenda of its own. This political agenda was focused on matters like the European Research Area, but also the strengthening of the political and economic significance of Ryl policy in general. Missions could be a means to give this significance higher visibility, but it implied tying missions to political goals that were largely defined in other policy areas. This tension was overcome by stressing the Ryl-centric nature of the missions to be pursued, as an argument that the control over missions remains largely within DG RTD.

At the same time, the engagement with other Directorates General was intensified in the preparatory debates about possible themes for future missions. The Foresight Correspondents Network, for instance, brings together key strategic thinkers from the majority of DGs, and it was closely involved in the implementation of the EC's foresight project BOHEMIA that helped prepare the thematic orientation of Horizon Europe, and thus also of possible missions. In other words, the network served as a soft coordination and harmonization mechanism between Ryl policy and various other EC policies already in the two years preceding the presentation of the Horizon Europe proposal.

\section{ASSESSMENT}

The introduction of the mission-oriented approach in Horizon Europe is based on the widely shared recognition that the implementation model of Horizon 2020 is not sufficient to achieve the expected impacts on societal challenges that were promised at the outset of Horizon 2020. This view is also backed by many Member States. 
While it is difficult to reconstruct precisely how and when the notion of 'missions' found its way into the Lamy Report, it was a concept under discussion in many different circles and tested in several Member States. In other words, the time was ripe for a new approach to implementing the framework programme; a necessity that was not particularly controversial in its general line of reasoning.

The situation is more complicated when it comes to the details of the mission-oriented approach. The overall appeal of the mission concept has led to an under-estimation of the governance challenges that a mission-oriented approach involves, from the selection of missions and the establishment of carrier organisations, to the coordination needs with demand-side sectoral policy and to coherent implementation of supply and demand side policies. The potential organizational interests within the Commission seem to have had an influence on the shaping of the more detailed specifications of the mission concept, but this process is still not finalised.

\section{THE SHAPING OF THE EUROPEAN INNOVATION COUNCIL}

\section{PATTERNS OF EMERGENCE}

The idea to establish a European Innovation Council (EIC) was announced for the first time by Carlos Moedas, Commissioner for Research, Science and Innovation, in his speech on 'Open Innovation, Open Science, Open to the World' in June $2015 .^{5}$ The concept of the EIC follows the perception of the European Commission of an ongoing deficit of the European innovation system, its innovation capacity to commercialize European high quality research and its ability to scale up innovative business, in particular in comparison with US ("European paradox").

Against this backdrop, the European Commission ran an open call for ideas in spring 2016 to develop further discussions, accompanied by numerous published stakeholder position papers (EC 2016a, EC 2016b). In that period, the spectrum of ideas varied from bundling innovation supporting instruments for reducing complexity ('one-stop-shop'), to allocating financial support for up-scaling or to concentrating on providing strategic intelligence and helping to reduce regulatory barriers in cooperation with other sectoral $\mathrm{DGs}$.

Subsequently, the 'High Level Group on Maximising the Impact of EU Research and Innovation Programmes' (Lamy et al, 2017) and particularly the 'High Level Group of Innovators' (HLG Innovators, 2018) stressed the need to support and invest in European high-risk, market-creating breakthrough innovations, particularly in 'deep tech' innovation (relying on science and engineering advances) and to overcome hindering factors in Europe. Examples are missing large investments over a significant period (venture capital is too small, fragmented, short term, with lack of critical mass, bank lending is inherently risk-adverse, policy funding perceived too complex), national and local initiatives too small to compete on global level, an incomplete single market and regulatory barriers. The
European Innovation Council was recommended to play a central role in implementing this focus and in providing a more simplified support scheme with bottom-up and multi-state approach of funding (grant-based at early stage for technology development and understanding pathways to commercialize, combination of grants and financial instruments when larger investment is needed). It should encourage collaboration and networking between innovators, firms, investors, etc. to stimulate scalingup on EU-level, stimulate collaboration with national and regional agencies and help innovators overcome regulatory barriers.

With the $1^{\text {st }}$ phase of an EIC pilot (launched in October 2017) as part of the Horizon 2020 Work Programme 2018-2020, the European Commission bundled existing funding instruments: SME Instrument, Fast Track to Innovation, Future and Emerging Technologies (FET) Open and the EIC Horizon Prizes accompanied by opportunities for networking, mentoring and coaching (EC 2018a).

The third pillar ("Open Innovation") of the proposed Horizon Europe programme (EC 2018b) basically follows this approach with the idea to provide financial support along a linear innovation cycle and to overcome the growing lack of equity funding for risk-prone companies dealing especially with deep-tech products. In addition, the envisaged InvestEU Programme is meant to mobilise further public and private investment by a factor of about 14 (EC 2018d). Concerning the EU added value it is argued that the only possibility to provide large-scale venture capital is to act on the EU-level, with more effectiveness and comprehensiveness (e.g. common regulation, synergies with other EU programmes) and with increasing coherence of the overall innovation ecosystem.

\section{THE RE-DISCOVERY OF A FRAME}

The main rationale used to underpin the call for a European Innovation Council is rooted in the "rediscovery" of the European paradox, a notion that was first coined in the mid-1990s, when the European Commission in its Green Paper on Innovation argued that 'one of Europe's major weaknesses lies in its inferiority in terms of transforming the results of technological research and skills into innovations and competitive advantages' (EC 1995, p. 5). The paradox, then, was suggesting that Europe was performing comparatively well in research, but was not successful in exploiting that potential economically.

A decade later, the existence of this paradox was increasingly questioned. Dosi et al (2006), for instance, argued that this paradox does not exist because Europe is behind the US also in scientific terms, for instance when looking at publication output per capita of population or of research personnel. Sachwald (2015), in a paper for the RISE group advising the European research commissioner, confirms this skepticism and speaks of a "double deficit", because although Europe produces more scientific publications than the US, these are less cited and less relevant to innovation. But also sectoral differences matter, because the US have their strongest scientific base in ICT, health and medicine, i.e. in areas where the mode of science-based innovation is particularly 
pronounced. Other reasons for the comparatively poor innovation performance are seen in less developed entrepreneurship and start-up cultures in Europe (Henrekson and Sanandaji 2017), and in the limited capacities of many European firms to absorb new scientific knowledge (Czarnitzki et al., 2009). Also still remaining barriers to a truly single market in Europe hamper the incentives for firms to innovate.

However, in spite of these insights, the European paradox was adopted as the guiding narrative underpinning the call for the creation of a European Innovation Council. In the course of the publication of the proposal for Horizon Europe and its impact assessment (EC 2018c), the Commission calls for action on the EU-level as future breakthrough innovation will be science-based ${ }^{6}$.

\section{EXTERNAL AND INTERNAL NETWORKS: HANDLING SKEPTICISM}

The round of consultation launched in 2016 raised support for the intention, but also criticism of the concept of the proposed EIC. The position papers of Member States, as well as the joint position of European Research Area and Innovation Committee (ERAC 2016) and reflection papers of the RISE group are interesting in this regard (RISE 2017).

Member States came up with a diverse range of proposals regarding the focusing of the EIC, reflecting on the 'call for ideas' during 2016 and in preparation for the interim evaluation of Horizon 2020 in the beginning of 2017. Their statements, as synthesised by Weber et al (2018a), suggests models ranging from i) EIC as supporting instrument for startups with high potential to scale-up on European and global level with entrepreneurs as the main beneficiaries, ii) EIC as supporting instrument for 'excellence in innovation' model (partly described in BMBF 2016) for a wider target group, iii) EIC as driver for the integration of existing instruments enabling synergies up to iv) EIC as key towards an integrated research and innovation policy through coordinating and thus enhancing policy coherence between research policy, innovation policy and sectoral policy fields. In other words, this latter model aims at taking into account policies and framework conditions innovation on the demand side of innovation (FP9 Think Tank 2017), thus stretching out to both European and national policy levels (IPM 2017).

Furthermore, the RISE expert group stressed that a new narrative 'From Innovation to Innovators' shall be one of the guiding principles of the EIC, aiming to align innovation policy in Europe with the characteristics of emerging models of innovation. Moreover, the EIC was meant to become a one-stop shop for innovators of any nature, be they driven by technology, new business modes, new design, customer experience, or organizational development (RISE 2017).

Criticism first of all addressed aspects concerning potential duplication of national funding initiatives for SMEs and therefore an unclear division of labour with national and regional policies. Other points of critique referred to the limited European added value because the EIC addresses individuals or individual firms rather than collaborative innovation activities across borders. A risk to overlap with activities of the European Institute for Innovation and Technology (EIT) was also criti- cised, as was the exclusion of universities and research organizations as potential sources of disruptive innovations with major scale-up potential. Finally, the ability of a public institution like the EC to identify excellent innovations/innovators with a market-creating potential and to manage risk capital and entrepreneurship-centric initiatives was questioned (RISE 2018b).

In phase 3 of the elaboration of the next framework programme, the recommendation of the High Level Group of Innovators (HLG Innovators 2018) and the proposal of the Commission for Horizon Europe were published, the $1^{\text {st }}$ phase of the EIC pilot had already started, the enhanced EIC pilot was not launched yet. In this period, the national position papers mainly followed the HLG of Innovators and its idea of supporting market creating 'deep tech' breakthrough innovations, by bringing together existing instruments under and EIC umbrella, bridging the 'valley of death' and combining funding and financial instruments to prepare innovators for large-scale private investment. Nevertheless, some items still remain unclear and are viewed with skepticism:

- Narrowing down of Scope: In contrast to the wide range of elements foreseen in the initial debates about the EIC, the proposed mission of the EIC has been narrowed down to science and technology-based market creating breakthrough innovation ('deep-tech') and on supporting entrepreneurs with potential to scale-up on European and global level. The coordination with Member State policies in order to complement national innovation initiatives without duplicating or even thwarting them, is essential. However, in referring to the proposed focus of the EIC (i.e. science and technology-based market creating breakthrough innovation), the RISE Group recommended in its recent paper (RISE 2018b) to carefully distinguish between 'deep-tech' and 'architectural' disruptive innovation. It further suggested the concept of 'Innovator Readiness Levels' instead of 'Technology Readiness Levels', in order to avoid the traditional linear mode of science-technology-market development.

- Complementarity with other segments of Horizon Europe: The proposed instruments of the EIC are based on a 'bottom up' approach and thus supporting innovators and innovations emerging within or at the crossroad of different sectors and disciplines. Interconnections and synergies with other pillars of Horizon Europe, in particular with the mission areas, and with the European Institute of Technology (EIT), while avoiding the creation of overlaps, have not yet been deepened in the discussions so far.

- Governance: The EIC portfolio is proposed to be managed following the ARPA-E approach (EC 2018c). The detailed concept and the requirements for dedicated programme managers and expert panels will be crucial. The participation of Member States for the implementation of the EIC and coordination with national agencies (co-funding partnerships are proposed by the Commission) will also be important. However, both aspects have not yet been developed in detail.

- Appropriateness of budget allocation within the "Open Innovation" pillar: A budget of EUR 10.5 billion for the European 
Innovation Council is foreseen, including up to EUR 0.5 billion for European Innovation Ecosystems to 'boost the effectiveness of the European innovation system' (EC 2018b, p5 of Annexes). In view of the importance of coordination with several actors in Member States and the need to strengthen the single market and overcome the European fragmentation (RISE 2018b), the amount of EUR 0.5 billion seems rather low.

\section{ASSESSMENT}

EU Member States have raised several concerns regarding the European Innovation Council, and as a result, the initial approach was considerably narrowed down to address a much more specific group of innovators than initially envisaged. Many other points of criticism have not been addressed, such as the extension of the single-beneficiary approach of the EIC, or the extensive role that the EC would assume in handling a variety of financial instruments which are well beyond the scope of funding instruments the $\mathrm{EC}$ is used to handle.

Possibly the most fundamental argument questioning the EIC concept as a whole concerns the main barriers to realizing market-creating breakthrough innovations in Europe, which some experts and Member States see in the remaining deficits of the European single market and the regulatory rigidities residing in sectoral policies, rather than in funding and advice to innovators. In other words, it is the wider ecosystem that hampers the success of market-creating breakthrough innovations. Interestingly, the ecosystem-oriented element of the EIC pillar of Horizon Europe is by far the smallest component in financial terms.

However, the strong support to the EIC concept from the Commissioner and his cabinet, backed largely by the high-level group installed, demonstrates that the EIC is a good example of rather limited influence of external voices, including those of the Member States, on the shaping of a key element of Horizon Europe.

\section{CONCLUSIONS}

To come back to our research question and hypothesis regarding the role and influence of Member States on the shaping of Horizon Europe, the two examples show a more differentiated picture than suggested by our initial hypothesis.

The EIC is an element that has been driven top-down from the Cabinet. Some suggestions from Member States were taken up (e.g. regarding the creation of an umbrella approach rather than a strong institution, or the narrowing of the scope of the EIC), while other major concerns and criticisms that could have questioned the EIC in its entirety were left aside (e.g. regarding the role of the entire ecosystem for market-creating innovations).

The mission-oriented approach, while still being controversially discussed with regard to its governance and the selection of priorities, was generally received positively by Member States and several other stakeholders. The rationale behind missions is largely shared, but major controversies arise at the level of national interests in potential themes and the role of Member States in the governance of subsequent implementation. However, it is still too early to give an assessment of the influence of Member States on the final shape of governance modalities and priority-setting.

\section{REFERENCES}

Andree, D., Weber, M., Llerena, P. (2015). A new role for EU Research and Innovation in the benefit of citizens: Towards an open and transformative Rgl policy, Policy Paper by the Research, Innovation, and Science Policy Experts (RISE), European Commission, Brussels.

Biegelbauer, P. (2013). Wie lernt die Politik - Lernen aus Erfahrung in Politik und Verwaltung. Wiesbaden, VS Verlag für Sozialwissenschaften.

Biegelbauer, P. and Weber, M. (2018). EU research, technological development and innovation policy. Handbook of European Policies: Interpretive Approaches to the EU. Hubert Heinelt and Sybille Münch (eds). Cheltenham, Gloucestershire, UK, Edward Elgar: 241-259.

BMBF (2016). European Innovation Council (EIC) - Position paper of the Federal Ministry of Education and Research (BMBF); Retrieved October 2, 2018 from: https://www.bmbf.de/files/EIC_position_paper_eng.pdf

BMBF (2018). Forschung und Innovation für die Menschen. Die HightechStrategie 2025, Bundeministerium für Bildung und Forschung, Berlin.

Czarnitzki, D. et al. (2009). The Nexus Between Science and Industry; Evidence from Faculty Inventions. Leuven: Department of Managerial Economics, Strategy and Innovation Working Paper.

Dosi, G. et al. (2006). The relationships between science, technologies and their industrial exploitation: An illustration through the myths and realities of the so-called 'European Paradox', Research Policy, 35(10), 1450-1464.

EC (1995). Green Paper on Innovation, European Commission, Brussels.

EC (2016a). Ideas for a European Innovation Council - Overview of Responses to the Call for Ideas, European Commission, Brussels, Retrieved October 2, 2018 from: https://ec.europa.eu/research/eic/pdf/eic_call_ for_ideas-overview.pdf

EC (2016b). Ideas for a European Innovation Council - Summary of a Validation Workshop with Stakeholders held on 13 July 2016. European Commission, Brussels, Retrieved October 2, 2018 from: https://ec.europa.eu/research/eic/pdf/workshop/eic_workshop_summary_report_final.pdf

EC (2018a). H2020 Work-Programme 2018-2020, Towards the next Framework Programme for Research and Innovation: European Innovation Council (EIC) pilot (revised version), European Commission, Brussels, Retrieved October 2, 2018 from: http://ec.europa.eu/research/participants/data/ref/h2020/wp/2018-2020/main/h2020-wp1820-eic_en.pdf

EC (2018b). Proposal for a Regulation of the European Parliament and of the Council establishing Horizon Europe - the Framework Programme for Research and Innovation. COM(2018) 435 final, European Commission, Brussels, Retrieved October 2, 2018 from: https://ec.europa.eu/commission/publications/research-and-innovation-including-horizon-europeiter-and-euratom-legal-texts-and-factsheets_en 
EC (2018c). Impact Assessment Accompanying the document establishing Horizon Europe, SWD(2018)307 final, European Commission, Brussels, Retrieved October 2, 2018 from: https://ec.europa.eu/commission/publications/research-and-innovation-including-horizon-europeiter-and-euratom-legal-texts-and-factsheets_en

EC (2018d). Factsheets on InvestEU, European Commission, Brussels, Retrieved October 2, 2018 from: https://ec.europa.eu/commission/publications/investeu-programme_en

EC (2019). 101 Ideas on the future of Research and Innovation in Europe, European Commission, Brussels, Retrieved March 6, 2019 from: https://ec.europa.eu/info/publications/101-ideas-future-research-andinnovation-europe_en

EFFLA (2012). How to design a European foresight process that contributes to a European challenge driven R\&I strategy process, Policy Brief No. 2, European Forum on Forward-Looking Activities, European Commission, Brussels.

ERAC (2016). ERAC Opinion on the idea of a European Innovation Council. ERAC 1209/16. Brussels, 14 July 2016.

ESIR (2017). Towards a mission-oriented research and innovation policy in the European Union. An ESIR memorandum, Report of the ESIR expert group, European Commission, Brussels, December 2017.

ESIR (2018). ESIR memorandum II. Implementing EU missions, Report of the ESIR expert group, European Commission, Brussels, October 2018.

European Council (2009). The Lund Declaration. Europe must focus on the Grand Challenges of our time, European Council, Brussels.

European Council (2015). Background paper to the Lund declaration 2015, European Council, Brussels.

FP9 Think Tank (2016). Theses Paper for shaping the next (9th) EU-RTD Framework Programme, Retrieved October 2, 2018 from: https://era. gv.at/object/document/2826/attach/FPg_Theses_Paper_endg_.pdf

FP9 Think Tank (2017). Fostering Impact and Sustainable Collaboration in FP9 within a new Common Research, Technology and Innovation Policy, Retrieved October 2, 2018 from: https://www.era.gv.at/object/ document/3117/attach/FP9_Theses_Paper_2_final.pdf

Henrekson, M. and Sanandaji, T. (2017), Schumpeterian Entrepreneurship in Europe Compared to Other Industrialized Regions. Stockholm: IFN Working Paper No. 1170.

HLG Innovators (2018). Funding - Awareness - Scale - Talent (FAST) Europe is back: Accelerating breakthrough innovation - Full set of recommendations from the Independent High-Level Group of Innovators on establishing a European Innovation Council. Retrieved October 2, 2018 from: https://ec.europa.eu/info/sites/info/files/eic_hlg_bz_web.pdf

IPM (2017). Draft Recommendations on the European Innovation Council, High Level Group on Innovation Policy Management, Brussels June 2017.
JIIP (2018). Mission-Oriented Research and Innovation: Inventory and characterisation of initiatives. Final report, Joint Institute for Innovation Research, European Commission, Brussels.

Lamy, $\mathbf{P}$ (2017). LAB - FAB - APP Investing in the European future we want. Report of the independent High Level Group on maximising the impact of EU Research \& Innovation Programmes, Retrieved October 2, 2018 from: https://ec.europa.eu/research/evaluations/pdf/archive/other _reports_studies_and_documents/hlg_2017_report.pdf\#view =fitgpagemode=none

Madelin, R. and Ringrose, D (eds.) (2016). Opportunity now: Europe's mission to innovate, European Commission, Brussels.

Mazzucato, M. (2018). Mission-oriented research \& innovation in the European Union: A problem-solving approach to fuel innovation-led growth, European Commission, Brussels.

Moedas, C. (2015). Open Innovation, Open Science, Open to the World. Speech at 'A new start for Europe: Opening up to an ERA of Innovation' Conference, Brussels 22 June 2015.

Pernicka, S., Feigl-Heihs, M. Gerstl, A., and Biegelbauer, P. (2002). Wie demokratisch ist die europäische Forschungs- und Technologiepolitik? Der politische Entscheidungsprozess zum fünften Forschungsrahmenprogramm aus österreichischer Perspektive. Baden-Baden, Nomos.

Pollak, J. and Slominski, P. (2006). Das Politische System der EU. Wien, WUV (UTB).

RISE (2017). Europe's Future: Open Innovation, Open Science, Open to the World. Reflections of the Research, Innovation and Science Policy Experts High Level Group.

RISE (2018a). Mission-Oriented Research and Innovation Policy. A RISE Perspective, European Commission, Brussels.

RISE (2018b). The academic underpinnings of the European Innovation Council. Summary and recommendations of the RISE subgroup on EIC, European Commission, Brussels.

Sachwald, F. (2015). Europe's twin deficits: Excellence and innovation in new sectors, Policy Paper by the Research, Innovation, and Science Policy Experts (RISE), European Commission, Brussels.

Soete, L., Veugeleurs, R., Sundgren, J.-E., and Glover, A. (2015): R\&। in times of crisis: dynamic interactions between R\&l, public finances and economic growth, RISE presentation, 01/2015.

Torfing, J. and Sørensen, E. (2014). "The European debate on governance networks: Towards a new and viable paradigm?" Policy and Society 33(4): 329-344.

Tsipouri, L. (2017). Pockets of excellence as drivers of regional growth. Policy paper of the RISE high-level workshop on "The impact of smart specialisation strategies on pockets of excellence and regional growth" (Crete, 6-8 0ctober 2015), European Commission, Brussels. 
Weber M., Rammer Ch., Dinges M., Dachs B., Hud M., and SteindI C. (2018a). Erkenntnis- und Wissenstransfer im Kontext europäischer F\&lPolitik. Studien zum deutschen Innovationssystem Nr. 12-2018.

Weber, M., Andreescu, L., Cuhls, K., Dragomir, B., Gheorghiu, R., Giesecke, S., Ricci, A., Rosa, A., Schaper-Rinkel, P., Sessa, C., Baiocco, S., Curaj, A., Giuffrè, G., Zern, R. (2018b): Transitions on the Horizon: Perspectives for the European Union's future research and innovation policies, Final Report of Project BOHEMIA (Beyond the Horizon. Foresight in Support of the EU's Future Policies on Research and Innovation), European Commission, Brussels.

All position papers, that have been considered in the analyses, were retrieved on October 2, 2018 from https://era.gv.at/directory/238 and https:// era.gv.at/directory/297

\section{AUTHORS}

\section{MATTHIAS WEBER}

Center for Innovation Systems and Policy, Austrian Institute of Technology Giefinggasse 4, Vienna, 1210 (Austria)

E: matthias.weber@ait.ac.at (corresponding author)

\section{KATJA LAMPRECHT}

Center for Innovation Systems and Policy, Austrian Institute of Technology Giefinggasse 4, Vienna, 1210 (Austria)

E: katja.lamprecht@ait.ac.at

\section{PETER BIEGELBAUER}

Center for Innovation Systems and Policy, Austrian Institute of Technology Giefinggasse 4, Vienna, 1210 (Austria)

E: peter.biegelbauer@ait.ac.at

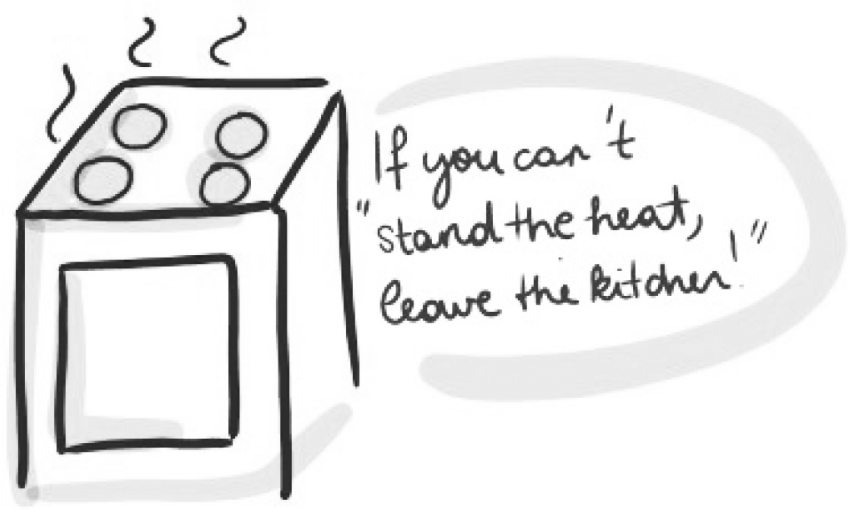

